\title{
Intellectual Property Clearinghouses and Investment in $\mathrm{R} \& \mathrm{D}^{*}$
}

\author{
Reiko Aoki \\ IER, \\ Hitotsubashi University \\ \& Department of Economics, \\ University of Auckland \\ aokirei@ier.hit-u.ac.jp \\ Aaron Schiff \\ IER, \\ Hitotsubashi University \\ aschiff@ier.hit-u.ac.jp
}

21 January 2008

\begin{abstract}
We examine the effects of third-party clearinghouses that license intellectual property on behalf of inventors when downstream uses of IP require licenses to multiple complementary innovations. We consider different simple clearinghouse royalty redistribution schemes, and different innovation environments. We show that clearinghouses generally increase incentives to invest in $R \& D$ as they increase efficiency in licensing. However, they may reduce expected profits of inventors who have the unique ability to develop a crucial component. We also show that clearinghouses also may increase or decrease expected welfare, and are more likely to be beneficial when $\mathrm{R} \& \mathrm{D}$ costs are relatively high, and/or the probability of success for inventors is relatively low.
\end{abstract}

Keywords: Intellectual property, licensing, clearinghouses, anticommons. $J E L$ :

\footnotetext{
${ }^{*}$ We thank the Japan Society for the Promotion of Science for financial support.
} 


\section{Introduction}

Many new innovations or products depend on multiple complementary upstream components. When different components are developed by independent inventors, licensing for downstream uses that combine these components may suffer from various inefficiencies dubbed the "tragedy of the anticommons" (Heller \& Eisenberg 1998, Buchanan \& Yoon 2000). Specifically, negotiating with multiple licensors may entail high transaction costs, and independent uncoordinated licensors may set royalties that are excessively high in total.

For example, development of a new genetic diagnostic medical test may require licensing multiple patented inventions, owned by different inventors, related to gene sequences, gene expression technologies, and so on (Van Overwalle et al 2006, OECD 2002). In such a case, high costs may be borne by end-users of the test, resulting in low levels of usage of the test, or the costs associated with licensing could be so high that development of the test becomes uneconomic entirely. As well as genetics, similar situations can also arise in information technology and communications industries, for example (Shapiro 2001, Aoki \& Nagaoka 2005).

In response to these licensing inefficiencies, a number of institutions and arrangements have emerged or been promoted, including patent pools, crosslicensing, collective rights organisations, and clearinghouses (Shapiro 2001, van Zimmeren et al 2006, Aoki \& Schiff 2008). In this paper we focus on third-party clearinghouses and examine the effects of different types of simple clearinghouse mechanisms on ex post licensing and ex ante incentives to invest in R\&D. Specifically, we model third-party clearinghouses that license complementary innovations jointly on behalf of member intellectual property owners.

We use a simple innovation framework where a downstream innovation or product requires the development of two complementary upstream components. A number of upstream research firms can invest in developing these components, and each has some probability of success. When multiple firms invest, there is some chance that multiple versions of either or both components will be developed independently. All successful innovators earn revenues by licensing their innovations to downstream users. After investment and the outcome of the random investment process is realised, each successful inventor can choose to license independently, or join a clear- 
inghouse and license his innovation jointly with the other members. The clearinghouse sets royalties to maximise the joint profits of its members.

In our model, introducing a clearinghouse generates a number of tradeoffs in terms of profits of research firms and welfare, which we explore. Ex post, after the outcome of investment is known, a clearinghouse increases welfare and profits if both components have a single inventor, as it overcomes the coordination problem that leads to the tragedy of the anticommons. However, if either or both components have multiple substitute inventions, the clearinghouse may increase profits but reduce welfare as it allows successful inventors to effectively collude and undermine the competition among themselves. Ex ante, before firms invest, expected profits of the research firms and expected welfare depend on the level of investment, which determines the probabilities of the different licensing market configurations ex post. In turn, the level of investment in R\&D is affected by the presence of a clearinghouse.

We use this model to evaluate two different royalty distribution schemes for a clearinghouse: equal distribution of royalties among members, and unequal distribution that gives a disproportionately larger fraction of royalties to a member who is the sole inventor of one component when the other component is competitive. We show that the unequal scheme improves welfare in all ex post licensing situations relative to the equal scheme, as it can guarantee the participation of all successful inventors. However, either scheme may be inferior to no clearinghouse if both components have multiple inventors with substitute inventions. We also consider two different innovation models within which we compare the ex ante performance of the two types of clearinghouse. In the first model, both components are symmetric and a large number of competitive research firms have the ability to develop each. In the second model, one component is unique and a single firm has the ability to develop it while the other component has many possible inventors.

We find that clearinghouses always increase ex ante incentives to invest in $R \& D$ by increasing ex post profits from licensing, except when one component can only be developed by one firm and the clearinghouse redistributes royalties equally. In this case the unique firm may not wish to join the clearinghouse, but competitive inventors of the other component will, which makes the former firm worse off. Clearinghouses may also increase or decrease ex ante expected welfare. A clearinghouse that distributes royal- 
ties unequally can always generate higher expected welfare for a given level of investment than no clearinghouse, as it can ensure participation of all successful innovators and solve the "anticommons" inefficiencies. However, a clearinghouse that distributes royalties equally does not always perform better than no clearinghouse, as it cannot achieve full participation of innovators. In particular, an equal clearinghouse only performs better than no clearinghouse when the level of investment in $R \& D$ is relatively low, so that the probability that one or both components has multiple successful inventors is not too high.

However, these welfare comparisons do not take account of the change in investment level induced by the clearinghouse. Once these are taken into account, even an unequal clearinghouse can reduce ex ante expected welfare if it results in an increase in investment beyond the socially desirable level. We use a numerical simulation to compare the equilibrium expected welfare of the different clearinghouse types under the different investment models. In general, a clearinghouse that redistributes royalties unequally performs better than one that distributes royalties equally, except for some subset of parameter values. In addition, the unequal clearinghouse performs better than no clearinghouse when costs of innovation are high, and/or the probability of an inventor's success is low, as these are the cases where improving licensing efficiency is most beneficial.

The organisation of the rest of this paper is as follows. In the next section we present a simple model of ex post licensing with a clearinghouse. Then in section 3 , we embed this ex post model in the two different random investment models, and compare different types of clearinghouse in terms of ex ante expected profits and welfare. In section 4 we perform further welfare comparisons using numerical simulations. Section 5 concludes.

\section{Effects of clearinghouses on ex post licensing}

There are two components or research tools, A and B, that are needed for the production of a downstream innovation or product. Upstream research firms invest in $\mathrm{R} \& \mathrm{D}$ to develop these components and earn royalties by licensing their innovations to downstream users. The two components are perfect complements and an inventor of either component cannot earn any royalties unless the other component has also been invented. There are a 
large number of research firms, each of which has the capacity to undertake a single research 'project' at some cost. The research firms are separated into two types: those that can develop A, and those that can develop B. Any individual project may result in the invention of one of the components or it may be unsuccessful and invent nothing. We allow for the possibility that equivalent versions of either component may be independently invented by multiple inventors.

A third-party clearinghouse may also exist and can license innovations on behalf of member inventors. All successful inventors have the option to join the clearinghouse or license independently. The clearinghouse seeks to maximise the total royalty revenues of its members from licensing, and distributes these revenues among its members according to a distribution rule that it announces in advance.

Given this setup, innovation and licensing takes place in two stages:

Stage 1: Each research firm decides whether or not to invest in an R\&D project and those that invest invent a component according to their type, with some probability.

Stage 2: Successful inventors simultaneously decide whether or not to join a clearinghouse or license independently, and then innovations are licensed by the clearinghouse and/or any independent inventors and royalties are paid by licensees.

In this section we describe our model of stage two of this process and find the ex post equilibrium payoffs of successful inventors and equilibrium welfare, for a given outcome of the first stage. The next section examines two alternative models of the first stage.

We look for a subgame perfect equilibrium. Provided that both components have been invented, successful inventors can earn royalties from licensing. The royalties that are generated depend on the number of independent licensors for each component. Let $\pi_{M}$ denote the total monopoly royalties obtained by licensing all successful inventions of both components jointly and let $\pi_{D}$ denote the duopoly royalties each component receives when there is one independent licensor for each component. Similarly, let $W_{M}$ denote the total downstream welfare that arises when both components are licensed jointly, $W_{D}$ denote the welfare level when the two components are licensed independently, and $W_{0}>W_{M}$ denote the welfare level when both components are licensed for zero royalties. Since components A and B 
are complements, we make the following assumption:

Assumption 1 The 'tragedy of the anticommons' reduces joint profits and welfare when the two components are licensed by two independent licensors compared to when they are licensed jointly: $\pi_{M} \geq 2 \pi_{D}$ and $W_{M} \geq W_{D}$.

The potential payoffs of successful inventors depend in part on the redistribution policy of the clearinghouse. We consider two different policies:

Definition 1 An equal clearinghouse distributes its royalty revenues equally among its members. If the clearinghouse earns $\pi$ and has $n$ members, each member receives $\pi / n$.

Definition 2 An unequal clearinghouse distributes disproportionate royalty revenues to a member (if any) who is the sole successful inventor of a component when the other component is competitive. If the clearinghouse earns $\pi$ and one component has a single inventor and the other component has $n \geq 2$ inventors, the monopoly inventor receives $z \pi$ and all other inventors receive $(1-z) \pi / n$, where $z \in\left(\frac{1}{n+1}, 1\right)$. In all other situations, the clearinghouse distributes revenues equally among its members.

Payoffs of successful inventors also depend on how many inventors there are of each component. There are three cases where downstream production is possible:

Case 1: Both components have a single successful inventor;

Case 2: One component has a single inventor and the other component has two or more independent inventors; and

Case 3: Both components have two or more independent inventors.

In cases 2 and 3, inventors of a competitive component cannot earn any royalties unless they all join a clearinghouse, since competition between them will drive royalties down to zero. We thus assume that such inventors always join either type of clearinghouse, if it exists. On the other hand, in cases 1 and 2 a monopoly inventor of a component may or may not want to join a clearinghouse. In case 1 , if both inventors license independently they each receive $\pi_{D}$, while if both join either type of clearinghouse they receive $\pi_{M} / 2$. If one inventor joins the clearinghouse but the other does not, the situation is effectively the same as where both do not join, and both receive $\pi_{D}$. Therefore, by Assumption 1, both successful inventors have a weakly dominant strategy to join either type of clearinghouse in case 1 . 


\begin{tabular}{|l|c|c|c|c|}
\hline Clearinghouse & $\boldsymbol{\pi}_{1}$ & $\boldsymbol{\pi}_{2}^{M}$ & $\boldsymbol{\pi}_{2}^{C}(n)$ & $\boldsymbol{\pi}_{3}\left(n_{A}, n_{B}\right)$ \\
\hline None & $\pi_{D}$ & $\pi_{M}$ & 0 & 0 \\
\hline Equal & $\pi_{M} / 2$ & $\pi_{D}$ & $\pi_{D} / n$ & $\pi_{M} /\left(n_{A}+n_{B}\right)$ \\
\hline Unequal & $\pi_{M} / 2$ & $z \pi_{M}$ & $(1-z) \pi_{M} / n$ & $\pi_{M} /\left(n_{A}+n_{B}\right)$ \\
\hline
\end{tabular}

Table 1: Equilibrium payoffs of successful inventors under different types of clearinghouse and different outcomes of the innovation process.

If case 2 arises, the successful inventors of the competitive component will all join either type of clearinghouse, as explained above. If the competitive component has $n$ inventors, the inventor of the monopoly component will join an equal clearinghouse if $\pi_{M} /(n+1) \geq \pi_{D}$ and will join an unequal clearinghouse if $z \pi_{M} \geq \pi_{D}$. To distinguish equal and unequal clearinghouses, we make the following assumption:

Assumption 2 A monopoly inventor of a component does not join an equal clearinghouse when there are $n \geq 2$ inventors of the other component, but does join an unequal clearinghouse. That is, $\pi_{M} \leq 3 \pi_{D}$ and $z \geq \pi_{D} / \pi_{M} \cdot{ }^{1}$

We can now summarise the equilibrium payoffs of successful inventors in stage 2, depending on which of the three cases above has arisen from the innovation process. Let $\pi_{1}$ be the royalties that a successful inventor receives in case 1 , let $\pi_{2}^{M}$ be the royalties that the monopoly inventor receives in case 2 , let $\pi_{2}^{C}(n)$ be the royalties that a successful inventor of the competitive component receives in case 2 when there are $n \geq 2$ inventors of that component, and let $\pi_{3}\left(n_{A}, n_{B}\right)$ be the royalties that a successful inventor receives in case 3 when there are $n_{A} \geq 2$ successful inventors of $\mathrm{A}$ and $n_{B} \geq 2$ successful inventors of $\mathrm{B}$.

Table 1 shows the values of these payoffs for different types of clearinghouse, as determined by the equilibrium of stage 2 of the model. In comparison with no clearinghouse, an equal clearinghouse increases an inventor's royalties if there are multiple inventors of the same component, or if there is only one inventor of both components. However, the clearinghouse decreases royalties from $\pi_{M}$ to $\pi_{D}$ when the inventor is the sole inventor of

\footnotetext{
${ }^{1}$ Such a value of $z$ achieves the clearinghouse's objective of maximising the total royalties of its members, since it ensures that all inventors join and consequently the clearinghouse royalties are $\pi_{M}$.
} 
a component but the other component is competitive. In this situation, the existence of the clearinghouse reduces competition among inventors of the competitive component, which benefits them but harms the sole inventor of the other component.

An unequal clearinghouse increases a successful inventor's royalties compared to no clearinghouse unless the inventor is the sole inventor of one component while the other component is competitive. In this case the value of $z$ is sufficient to induce the monopoly inventor to join the clearinghouse, but she is still worse off compared to when no clearinghouse exists, because the clearinghouse gives some fraction of $\pi_{M}$ to the competitive inventors of the other component. An unequal clearinghouse may also make successful inventors better or worse off compared to an equal clearinghouse. If, for example, $\mathrm{A}$ has a single inventor but $\mathrm{B}$ is competitive, the inventors of $\mathrm{B}$ receive $\pi_{D} / n_{B}$ under an equal clearinghouse, but $(1-z) \pi_{M} / n_{B}$ under an unequal clearinghouse. Since $z \geq \pi_{D} / \pi_{M}$ to attract the inventor of A to join the unequal clearinghouse, this reduces the payoffs of the inventors of $\mathrm{B}$ relative to the equal clearinghouse.

Similarly, let $W_{1}, W_{2}$ and $W_{3}$ be the equilibrium welfare levels attained from licensing in cases 1,2 and 3 respectively. Table 2 shows the welfare levels (ignoring $\mathrm{R} \& \mathrm{D}$ costs) that result under each type of clearinghouse in each of the three cases. Compared to no clearinghouse, an equal clearinghouse improves welfare when both components have a single inventor (case 1), but reduces welfare in all other cases, as the clearinghouse allows multiple inventors of the same component to reduce competition among themselves. An unequal clearinghouse with an appropriate value of $z$ always attracts all inventors to join, and thus always achieves the welfare level $W_{M}$. Compared to no clearinghouse, this increases welfare when both components have a single inventor (case 1), but reduces welfare when both components have multiple inventors (case 3), and leaves welfare unchanged in case 2 . In every case an unequal clearinghouse generates at least as much welfare as an equal clearinghouse, and outperforms it when one component has a single inventor and the other has multiple inventors (case 2). 


\begin{tabular}{|l|c|c|c|}
\hline Clearinghouse & $\mathbf{W}_{1}$ & $\mathbf{W}_{2}$ & $\mathbf{W}_{3}$ \\
\hline None & $W_{D}$ & $W_{M}$ & $W_{0}$ \\
\hline Equal & $W_{M}$ & $W_{D}$ & $W_{M}$ \\
\hline Unequal & $W_{M}$ & $W_{M}$ & $W_{M}$ \\
\hline
\end{tabular}

Table 2: Equilibrium welfare (ignoring investment costs) from licensing under different types of clearinghouse and different outcomes of the innovation process.

\section{Effects of clearinghouses on ex ante expected profits and welfare}

In this section we examine and compare clearinghouses under two alternative models of the investment and innovation process in stage 1 of the game.

\subsection{Investment model 1: All projects are equal}

In this model, every research project $\operatorname{costs} c$ and has the same chance of developing a component or developing nothing. Research firms and projects are exogenously specialised towards the development of A or B and a large number of firms are capable of undertaking projects of each type. Let $N_{A}$ and $N_{B}$ be the total number of projects undertaken to develop $\mathrm{A}$ and $\mathrm{B}$ respectively. The success of any project is independent of that of any other project. Given that $N_{i} \geq 1$ projects are undertaken for component $i=A, B$, the probability that $n_{i} \leq N_{i}$ successfully develop the component is denoted by $P\left(n_{i}, N_{i}\right)$, where $\sum_{n_{i}=0}^{N_{i}} P\left(n_{i}, N_{i}\right)=1$ and $\lim _{N_{i} \rightarrow \infty} P\left(n_{i}, N_{i}\right)=0$ for all $n_{i} \in\left\{0,1, \ldots, N_{i}\right\}$.

Since the components are identical, we consider symmetric situations where $N_{A}=N_{B}=N$, thus $2 N$ projects are undertaken in total. The expected profit of a research firm given that $N$ research projects are undertaken for each component is denoted $\pi(N)$. The probability that there is one successful inventor of each component (case 1) and a given research firm is one of these is $\frac{1}{N} P(1, N)^{2}$. The probability that a research firm is the sole inventor of their component while the other component has $n \geq 2$ inventors (case 2, monopoly) is $\frac{1}{N} P(1, N) P(n, N)$. The probability that a research firm is one of $n \geq 2$ inventors of their component while the other component has a single inventor (case 2 , competitive) is $\frac{n}{N} P(n, N) P(1, N)$. The proba- 
bility that a research firm is one of $m \geq 2$ inventors of their component while the other component has $n \geq 2$ inventors (case 3) is $\frac{m}{N} P(m, N) P(n, N)$. Considering all possibilities under which cases 1, 2 and 3 can occur, using the payoff definitions from Table 1, the expected profit of a research firm is

$$
\begin{aligned}
\pi(N)= & \frac{1}{N} P(1, N)^{2} \pi_{1}+\frac{1}{N} P(1, N) \sum_{n=2}^{N} P(n, N)\left[\pi_{2}^{M}+n \pi_{2}^{C}(n)\right] \\
& +\sum_{m=2}^{N} \sum_{n=2}^{N} \frac{m}{N} P(m, N) P(n, N) \pi_{3}(m, n)-c .
\end{aligned}
$$

Let $\pi^{N C}(N), \pi^{E C}(N)$ and $\pi^{U C}(N)$ be a research firm's expected profit under no clearinghouse, an equal clearinghouse and an unequal clearinghouse respectively given that $N$ projects are undertaken for each component. Recall from Table 1 that the existence of a clearinghouse potentially involves both ex post gains and losses for research firms. The following proposition shows that, in terms of ex ante expected profits, the gains always outweigh the losses, for any given $N$.

Proposition 1 Given $N$, the expected profit of a research firm is highest with an unequal clearinghouse and lowest with no clearinghouse, that is, $\pi^{U C}(N) \geq \pi^{E C}(N) \geq \pi^{N C}(N)$ for all $N \geq 1$.

Proof. Substituting payoffs from Table 1 into $(1), \pi^{U C}(N) \geq \pi^{E C}(N)$ if $P(1, N) \sum_{n=2}^{N} P(n, N)\left[\pi_{M}-2 \pi_{D}\right] \geq 0$, which is true by Assumption 1. Similarly, $\pi^{U C}(N) \geq \pi^{N C}(N)$ is equivalent to $P(1, N)^{2}\left[\frac{1}{2} \pi_{M}-\pi_{D}\right]+$ $\sum_{m=2}^{N} \sum_{n=2}^{N} \frac{m}{m+n} P(m, N) P(n, N) \pi_{M} \geq 0$, which is also true by Assumption 1. Finally, $\pi^{E C}(N) \geq \pi^{N C}(N)$ if $f(N) \pi_{M} \geq g(N) 2 \pi_{D}$ where

$$
g(N)=P(1, N)^{2}-2 P(1, N) \sum_{n=2}^{N} P(n, N)
$$

and

$$
f(N)=g(N)+2 \sum_{m=2}^{N} \sum_{n=2}^{N} \frac{m}{m+n} P(m, N) P(n, N) .
$$

Since $\pi_{M} \geq 2 \pi_{D}$ and $f(N) \geq g(N)$, we have $\pi^{E C}(N) \geq \pi^{N C}(N)$ if $f(N) \geq$ 0 for all $N \geq 1$. To show this is true, note that $f(N) \geq 0$ is the same as

$$
1-2 \sum_{n=2}^{N} R(n, N)+2 \sum_{m=2}^{N} \sum_{n=2}^{N} \frac{m}{m+n} R(m, N) R(n, N) \geq 0,
$$


with $R(n, N)=P(n, N) / P(1, N)$, and this last inequality can be rewritten as $\left[\sum_{n=2}^{N} R(n, N)-1\right]^{2} \geq 0$, which is true. ${ }^{2}$

Since research firms are competitive, the equilibrium number of projects, $N^{*}$, satisfies $\pi\left(N^{*}\right) \geq 0$ and $\pi\left(N^{*}+1\right)<0$. In this model, either type of clearinghouse always increases the ex ante profits of a research firm, and thus generates greater investment in $\mathrm{R} \& \mathrm{D}$ compared to no clearinghouse, for a given level of per-project costs.

Using the welfare definitions from Table 2, expected total welfare given that $N$ research projects are undertaken for each component is

$$
\begin{aligned}
W(N)= & P(1, N)^{2} W_{1}+2 P(1, N) \sum_{n=2}^{N} P(n, N) W_{2} \\
& +\sum_{m=2}^{N} \sum_{n=2}^{N} P(m, N) P(n, N) W_{3}-2 N c
\end{aligned}
$$

Let $W^{N C}(N), W^{E C}(N)$ and $W^{U C}(N)$ be the total expected welfare with no clearinghouse, an equal clearinghouse and an unequal clearinghouse respectively. The following proposition compares the expected welfare gains and losses from introducing a clearinghouse.

Proposition 2 Given $N$, expected welfare with an unequal clearinghouse is always higher than that with an equal clearinghouse: $W^{U C}(N) \geq W^{E C}(N)$ for all $N \geq 1$. In addition, expected welfare with no clearinghouse is highest when $N$ is sufficiently large but lowest when $N$ is small: $W^{U C}(N) \geq$ $W^{E C}(N) \geq W^{N C}(N)$ for sufficiently small $N$, and $W^{N C}(N) \geq W^{U C}(N) \geq$ $W^{E C}(N)$ for sufficiently large $N$.

Proof. From Table 2 it is clear that $W^{U C}(N) \geq W^{E C}(N)$ since $W_{M} \geq W_{D}$. From Table 2 and $(2), W^{U C}(N) \geq W^{N C}(N)$ if

$$
P(1, N)^{2}\left[W_{M}-W_{D}\right] \geq \sum_{m=2}^{N} \sum_{n=2}^{N} P(m, N) P(n, N)\left[W_{0}-W_{M}\right] .
$$

Since $\sum_{n=2}^{N} P(n, N)=1-P(0, N)-P(1, N)$, this can be rewritten as

$$
\left[\frac{1-P(0, N)-P(1, N)}{P(1, N)}\right]^{2} \leq \frac{W_{M}-W_{D}}{W_{0}-W_{M}} .
$$

\footnotetext{
${ }^{2}$ This follows from the fact that given some numbers $x_{1}, \ldots, x_{N}$,
}

$$
2 \sum_{i=1}^{N} \sum_{j=1}^{N} \frac{i}{i+j} x_{i} x_{j}=\sum_{i=1}^{N} \sum_{j=1}^{N} x_{i} x_{j}=\left[\sum_{i=1}^{N} x_{i}\right]^{2}
$$


The right-hand side of this inequality is positive since $W_{0} \geq W_{M} \geq W_{D}$. If $N=1$ the left-hand side equals zero since $P(0,1)+P(1,1)=1$, so $W^{U C}(1)>W^{N C}(1)$. At higher values of $N$, the left-hand side eventually becomes arbitrarily large, since $\lim _{N \rightarrow \infty} P(n, N)=0$ for all $n$, thus for sufficiently large $N$ this inequality does not hold and $W^{U C}(N)<W^{N C}(N)$.

Finally, $W^{E C}(N) \geq W^{N C}(N)$ if

$$
\left[1-2 \sum_{n=2}^{N} \frac{P(n, N)}{P(1, N)}\right]\left[W_{M}-W_{D}\right] \geq \sum_{m=2}^{N} \sum_{n=2}^{N} \frac{P(m, N)}{P(1, N)} \frac{P(n, N)}{P(1, N)}\left[W_{0}-W_{M}\right]
$$

which can be rewritten as

$$
\frac{P(1, N)[2 P(0, N)+3 P(1, N)-2]}{[1-P(0, N)-P(1, N)]^{2}} \geq \frac{W_{0}-W_{M}}{W_{M}-W_{D}} .
$$

The right-hand side is positive while the left-hand side is arbitrarily large at $N=1$ and converges to zero as $N$ increases. Thus $W^{E C}(1)>W^{N C}(1)$, and $W^{E C}(N) \leq W^{N C}(N)$ for sufficiently large $N$.

Intuitively, an unequal clearinghouse always generates more welfare than an equal clearinghouse because, given that both components are invented, it guarantees that the welfare level with a single licensor, $W_{M}$, is achieved, while the equal clearinghouse only achieves $W_{D} \leq W_{M}$ in the case when one component has a single inventor while the other component has multiple inventors. However, no clearinghouse outperforms both types of clearinghouse when $N$ is large. This is because when $N$ is large, the most likely outcome is that both components have multiple inventors (case 3). In this case, with no clearinghouse, competition among inventors drives royalties for both components to zero, and the highest possible welfare level, $W_{0}$, is achieved from licensing. Similarly, no clearinghouse generates low welfare levels relative to both types of clearinghouse when $N$ is low, because then it is more likely that both components have a single licensor and thus joint licensing through a clearinghouse achieves $W_{M}$ instead of $W_{D}$.

Propositions 1 and 2 also imply that there is a potential tradeoff in terms of the equilibrium effects of a clearinghouse on expected welfare. For any given level of investment in R\&D (given $N$ ), introducing some sort of clearinghouse may or may not raise expected welfare. However, even if welfare increases given $N$, it is not guaranteed to increase once the increase in investment is taken into account, since $R \& D$ is costly. Without making additional assumptions it is impossible to solve the zero-profit condition on (1) to determine the equilibrium $\mathrm{R} \& \mathrm{D}$ investment and perform comparative statics 
analysis between the different clearinghouse regimes. We therefore use a numerical simulation model in section 4 to examine this tradeoff further.

There may also be a conflict between the incentives of existing intellectual property owners and research firms who have not yet invested, in terms of their willingness to use and support a clearinghouse. For example, Table 1 shows that if case 2 arises, the monopoly inventor is made worse off by the existence of either type of clearinghouse relative to when there is no clearinghouse. Sole successful inventors of an essential component for a downstream innovation may thus be reluctant to use a clearinghouse if it means that they have to share some royalties with competitive inventors of another component. On the other hand, Proposition 1 showed that the $e x$ ante expected profit of a research firm is always increased by the creation of a clearinghouse. Thus innovators who have not yet invested are more likely to support the creation of the clearinghouse, even if, ex post, there is some chance that they will have a monopoly over their component.

\subsection{Investment model 2: Component $\mathrm{A}$ is unique}

In this version of the model, a single research firm ('firm A') has the unique ability to develop component A. We assume its success is deterministic, and it can develop $\mathrm{A}$ for certain if it invests $c_{A}$. As before, there are also competitive research firms that each can undertake one research project to try to develop $\mathrm{B}$ at a cost of $c_{B}$. Given that $N$ projects are undertaken by these component $\mathrm{B}$ firms, the probability that $n$ of them are successful is $P(n, N)$. We let $\pi_{A}(N)$ denote firm A's expected profit given that it invests and given that $N$ projects invest in $\mathrm{B}$, and let $\pi_{B}(N)$ denote the expected profit of an individual project aimed at developing $B$ given that firm A invests.

Of licensing cases 1, 2 and 3 considered earlier, only 1 and 2 are possible in this model. Given that firm A invests, the probability that there is a single inventor of both components (case 1 ) is $P(1, N)$ and the probability that A has a single inventor while $\mathrm{B}$ has multiple inventors (case 2 ) is $P(n, N)$ for $n \geq 2$. Thus we have

$$
\pi_{A}(N)=P(1, N) \pi_{1}+\sum_{n=2}^{N} P(n, N) \pi_{2}^{M}-c_{A} .
$$


Proposition 3 Given N, Firm A is always better off under an unequal clearinghouse compared to an equal clearinghouse when Assumption 2 holds. In addition, firm A's expected profit is highest with no clearinghouse for relatively high values of $N$, but is highest with an unequal clearinghouse for relatively low values of $N$. That is, $\pi_{A}^{N C}(N) \geq \pi_{A}^{U C}(N) \geq \pi_{A}^{E C}(N)$ for sufficiently high $N$ and $\pi_{A}^{U C}(N) \geq \pi_{A}^{E C}(N) \geq \pi_{A}^{N C}(N)$ for sufficiently low $N$.

Proof. From Table 1 and (3), $\pi_{A}^{U C}(N) \geq \pi_{A}^{E C}(N)$ if

$$
[1-P(0, N)-P(1, N)]\left(z \pi_{M}-\pi_{D}\right) \geq 0
$$

which is true for all $N$ under Assumption 2. Similarly $\pi_{A}^{U C}(N) \geq \pi_{A}^{N C}(N)$ if

$$
\frac{P(1, N)}{1-P(0, N)-P(1, N)} \geq \frac{2(1-z) \pi_{M}}{\pi_{M}-2 \pi_{D}} .
$$

The right-hand side of this expression is positive by assumption. The lefthand side is arbitrarily large when $N=1$, so $\pi_{A}^{U C}(1) \geq \pi_{A}^{N C}(1)$. As $N$ increases, the left-hand side converges to zero, since $\lim _{N \rightarrow \infty} P(n, N)=$ 0 for all $n$, thus for sufficiently large $N, \pi_{A}^{U C}(N)<\pi_{A}^{N C}(N)$. Finally, $\pi_{A}^{E C}(N) \geq \pi_{A}^{N C}(N)$ if

$$
\frac{P(1, N)}{1-P(0, N)-P(1, N)} \geq \frac{\pi_{M}-\pi_{D}}{\frac{1}{2} \pi_{M}-\pi_{D}} .
$$

Again the right-hand side is positive and this expression holds at $N=1$, but the left-hand side converges to zero as $N$ increases.

Firm A always prefers an unequal clearinghouse to an equal one provided that the unequal clearinghouse sets $z$ high enough so that it induces firm A to join ex post. In comparison to no clearinghouse, firm A prefers a clearinghouse only when $N$ is small and the probability that component $\mathrm{B}$ has a single inventor is relatively large. In that case, firm A benefits from the existence of a clearinghouse because joint licensing with a single inventor of B increases A's profits. However, if B has multiple inventors, competition among them drives the royalty for $\mathrm{B}$ to zero, and firm $\mathrm{A}$ is able to appropriate all of the monopoly profits from licensing when there is no clearinghouse. If an equal clearinghouse exists, in such a situation the inventors of B will license jointly, which hurts firm A, while if an unequal clearinghouse exists, firm A also joins, but has to share some royalties with 
the inventors of B. In either case, firm A is worse off compared to when no clearinghouse exits.

The expected profit of a research firm that develops B is

$$
\pi_{B}(N)=\frac{1}{N} P(1, N) \pi_{1}+\sum_{n=2}^{N} \frac{n}{N} P(n, N) \pi_{2}^{C}(n)-c_{B} .
$$

Proposition 4 For any given $N$, a research firm that invests in component $B$ is always better off under either an equal or unequal clearinghouse compared to no clearinghouse. Such a firm is better off under an unequal clearinghouse compared to an equal clearinghouse if $z \leq 1-\pi_{D} / \pi_{M}$.

Proof. From Table 1 and (4), it is straightforward to verify that the assumption that $\pi_{M} \geq 2 \pi_{D}$ guarantees that $\pi_{B}^{E C}(N) \geq \pi_{B}^{N C}(N)$ and $\pi_{B}^{U C}(N) \geq \pi_{B}^{N C}(N)$ for all $N \geq 1$. We also have $\pi_{B}^{U C}(N) \geq \pi_{B}^{E C}(N)$ if

$$
\frac{1}{N}[1-P(0, N)-P(1, N)]\left[(1-z) \pi_{M}-\pi_{D}\right] \geq 0
$$

which is true provided that $z \leq 1-\pi_{D} / \pi_{M}$.

Having either type of clearinghouse never makes a component $B$ research firm worse off because the firm always gets a strictly higher ex post payoff whatever the outcome of the random innovation process compared to when there is no clearinghouse in this model, as shown in Table 1. Whether an unequal clearinghouse is better than an equal clearinghouse for these firms depends on the fraction of revenues that the unequal clearinghouse gives to firm A. Both types of clearinghouse give the same payoff, $\pi_{M} / 2$, to a component B inventor when there is a single successful inventor of that component. When there are multiple successful inventors of $\mathrm{B}$, an equal clearinghouse does not induce firm $\mathrm{A}$ to join, so an inventor of $\mathrm{B}$ gets $\pi_{D} / n$. With an unequal clearinghouse, firm A joins and the clearinghouse revenues rise to $\pi_{M}$, but a fraction $z$ is given to firm $\mathrm{A}$ to induce it to join. Thus component $\mathrm{B}$ inventors are only better off relative to an equal clearinghouse if $z$ is not too large. Note that there is always some range of $z$ that both induces firm $\mathrm{A}$ to join an unequal clearinghouse and makes component $\mathrm{B}$ inventors better off compared to an equal clearinghouse. This requires $z \in$ $\left[\pi_{D} / \pi_{M}, 1-\pi_{D} / \pi_{M}\right]$, which is always feasible since $\pi_{D} / \pi_{M} \leq \frac{1}{2}$.

Combining Propositions 3 and 4 , the existence of a clearinghouse increases the incentive of component $\mathrm{B}$ firms to invest in $\mathrm{R} \& \mathrm{D}$, but may 
increase or decrease firm A's incentive to invest. In addition, if the introduction of a clearinghouse increases investment by component $\mathrm{B}$ firms, this in turn may increase or decrease firm A's ex ante profit. Overall, introducing a clearinghouse will increase investment in component $\mathrm{B}$, but has an ambiguous effect on firm A's incentive to invest.

As in the first investment model, there may also be a conflict between existing and potential innovators. For example, if firm A has already invested, it will be opposed to a clearinghouse if there are multiple inventors of component B. This model also generates a conflict between firm A and component B firms. Under an unequal clearinghouse, if firm A has already invested it will want $z$ to be as high as possible. However, having no clearinghouse or a high value of $z$ reduces the expected profits of a component $B$ research firm. On the other hand, if investment has not yet taken place, ex ante firm A may be willing to sacrifice some of its ex post profits, by supporting a clearinghouse or a lower value of $z$, to give greater incentive to the component B firms to invest, since A cannot earn any revenues unless B is also invented. We examine these tradeoffs further numerically in the next section.

The expected welfare given that firm A invests and $N \geq 1$ other firms invest is

$$
W(N)=P(1, N) W_{1}+\sum_{n=2}^{N} P(n, N) W_{2}-c_{A}-N c_{B} .
$$

Proposition 5 Given $N$, expected welfare is always highest with an unequal clearinghouse, under Assumption 2. An equal clearinghouse generates higher welfare compared to no clearinghouse only for sufficiently low $N$. That is, $W^{U C}(N) \geq W^{E C}(N) \geq W^{N C}(N)$ for sufficiently low $N$, and $W^{U C}(N) \geq$ $W^{N C}(N) \geq W^{E C}(N)$ for high $N$.

Proof. From Table 2 and (5), it is straightforward to show that $W_{M} \geq W_{D}$ implies $W^{U C}(N) \geq W^{E C}(N)$ and $W^{U C}(N) \geq W^{N C}(N)$ for all $N \geq 1$. Similarly, $W^{E C}(N) \geq W^{N C}(N)$ if

$$
[2 P(1, N)+P(0, N)-1]\left[W_{M}-W_{D}\right] \geq 0 .
$$

This is true at $N=1$ since $P(1,1)+P(0,1)=1$ and $W_{M} \geq W_{D}$. However the first bracket converges to -1 as $N$ becomes large, thus $W^{E C}(N)<$ $W^{N C}(N)$ for sufficiently large $N$. 
In this model the unequal clearinghouse always does best in terms of expected welfare. This is because with a unique inventor for component A, a situation in which there are multiple inventors of both components never arises, and the welfare level $W_{0}$ is never achieved. Thus since the unequal clearinghouse guarantees the welfare level $W_{M}$, provided that $z$ is high enough that firm A joins, it always performs better than either no clearinghouse or an equal clearinghouse. On the other hand, an equal clearinghouse only outperforms no clearinghouse if $N$ is low so that the chance that component B has a single inventor is relatively high. When $N$ is large, it is relatively likely that competition among inventors of $\mathrm{B}$ will drive the royalty for that component to zero, resulting in welfare level $W_{M}$ with no clearinghouse. However, an equal clearinghouse permits multiple inventors of B to reduce competition, resulting in welfare of $W_{D}$.

Finally, as in model 1, the ranking of expected welfare in Proposition 5 takes the level of investment in $\mathrm{R} \& \mathrm{D}$ as given. While an unequal clearinghouse always results in the highest expected welfare level given $N$, once the change in investment induced by the clearinghouse is taken into account, a clearinghouse may either increase or decrease ex ante expected welfare.

\subsection{Summary}

The above analysis shows that clearinghouses have some different effects in the two different investment models. Here we summarise the results we have obtained so far and compare clearinghouses versus no clearinghouse in terms of ex ante and ex post profits and welfare.

Ex ante profit: In model 1, introducing a clearinghouse increases ex ante profit for all $N$, while in model 2 ex ante profit always increases for component B firms, but only increases for firm A when $N$ is relatively low.

Ex post profit: In both models, introducing a clearinghouse increases the ex post profit of inventors of a component that has multiple inventors. It also increases inventors' profits when both components have a single inventor. Thus, ex post, component B inventors are always better off from introducing a clearinghouse in model 2. However, a clearinghouse reduces the ex post profit of the sole inventor of one component when the other component is competitive. Thus any research firm has a chance of being made worse off in model 1, and firm A may be made worse off in model 2 if $\mathrm{B}$ is competitive.

Ex ante welfare: In model 1, either an equal or unequal clearinghouse 
increases welfare relative to no clearinghouse when $N$ is low, but decreases welfare when $N$ is high. In model 2 , the same is true for an equal clearinghouse, but an unequal clearinghouse always increases ex ante welfare relative to no clearinghouse, provided that firm A invests.

Ex post welfare: Either type of clearinghouse increases ex post welfare in both models when both components have a single inventor. When one component has a single inventor and the other component has multiple inventors, under both models an equal clearinghouse decreases ex post welfare while an unequal clearinghouse leaves welfare unchanged. If both components have multiple inventors, which only arises in model 1 , both types of clearinghouse reduce ex post welfare.

\section{Simulation analysis}

In this section we use numerical simulations of our two investment models to investigate further the tradeoffs between welfare and incentives to invest that were identified above. For the simulation we assume that total demand for licenses from both components is linear and is given by $Q=100-\rho$ where $Q$ is the number of licenses sold and $\rho$ is the total per-unit royalty for licensing both $\mathrm{A}$ and $\mathrm{B}$. Under this assumption, the royalty revenues of a licensor setting a royalty of $r_{i}$ is $R_{i}=(100-\rho) r_{i}$ where $\rho=\sum r_{i}$, and total welfare generated by licensing is $W=50(1-\rho)(1+\rho)$. When there is a single licensor, $\rho$ is chosen to maximise $(100-\rho) \rho$, which gives $\rho_{M}=\frac{1}{2}$. Under duopoly, it is straightforward to show that the noncooperative equilibrium royalties are $\rho_{D}=\frac{2}{3}$. These give the parameter values shown in Table 3 . It is clear that these values satisfy Assumption 1. To satisfy Assumption 2, the unequal clearinghouse must set $z \in\left(\frac{4}{9}, 1\right)$.

We also assume that the random investment processes are binomial, with the probability of success of any given project given by $\sigma$, thus

$$
\operatorname{Pr}(n, N)=\sigma^{n}(1-\sigma)^{N-n} \frac{N !}{n !(N-n) !} .
$$

The exogenous parameters of the simulation model are therefore the success probability $\sigma$, the unequal clearinghouse parameter $z$, and the investment costs $c$ (in model 1) and $c_{A}$ and $c_{B}$ (in model 2). Simulations were programmed in $R$ 2.6.0 for Windows, and source codes are available from the authors on request. 


\begin{tabular}{|l|c|c|c|c|c|}
\hline Parameter & $\pi_{M}$ & $\pi_{D}$ & $W_{0}$ & $W_{M}$ & $W_{D}$ \\
\hline Value & $\frac{100}{4}$ & $\frac{100}{9}$ & 50 & $\frac{75}{2}$ & $\frac{250}{9}$ \\
\hline
\end{tabular}

Table 3: Model parameters for linear demand for licensing, where $Q=$ $100-\rho$ with $\rho$ the total per-unit royalty.

\subsection{Model 1 simulations}

The key question from model 1 is how introducing either type of clearinghouse affects equilibrium investment in the two components and hence the expected equilibrium welfare level. We examined this by using a simulation that iterates over a grid of values of $c$ and $\sigma$. For each pair of parameters the equilibrium investment level is found by evaluating (1) and using a numerical search algorithm to find the highest level of $N$ at which $\pi(N) \geq 0$ and $\pi(N+1)<0$. With binomial success probabilities, $\pi(N)$ eventually approaches $-c$ as $N$ becomes large, since the probability that any individual project is successful tends to zero. Thus provided that $\pi(N)>0$ for some relatively low values of $N$, an equilibrium with investment in both components exists. Otherwise, we recorded the equilibrium as $N=0$, representing no investment.

For each combination of $c$ and $\sigma$, this procedure was repeated assuming no clearinghouse, an equal clearinghouse and an unequal clearinghouse, and the equilibrium level of investment was recorded in each case. ${ }^{3}$ Under each type of clearinghouse, the welfare level at the equilibrium investment level was calculated by evaluating (2). Thus for each combination of $c$ and $\sigma$, we record six values: the equilibrium investment level and the equilibrium welfare level under no clearinghouse and each of the two types of clearinghouse. We allowed $c$ to vary between 0.1 and 10 in increments of 0.01 and $\sigma$ to vary between 0.05 and 0.95 in increments of 0.001 , thus we conducted a total of 892, 891 simulations for model 1.

Figure 1 illustrates a single example simulation of model 1 , for the parameter values shown in Table 3, and assuming $c=2.5$ and $\sigma=0.7$. The left panel shows the expected profit of an individual research firm under each type of clearinghouse, as a function of the number of projects that are undertaken for each component. As in Proposition 1, introducing a clear-

\footnotetext{
${ }^{3}$ Note that in model 1 with an unequal clearinghouse, it is straightforward to show that expected profits are independent of $z$, by substituting payoff from Table (1) into (1).
} 

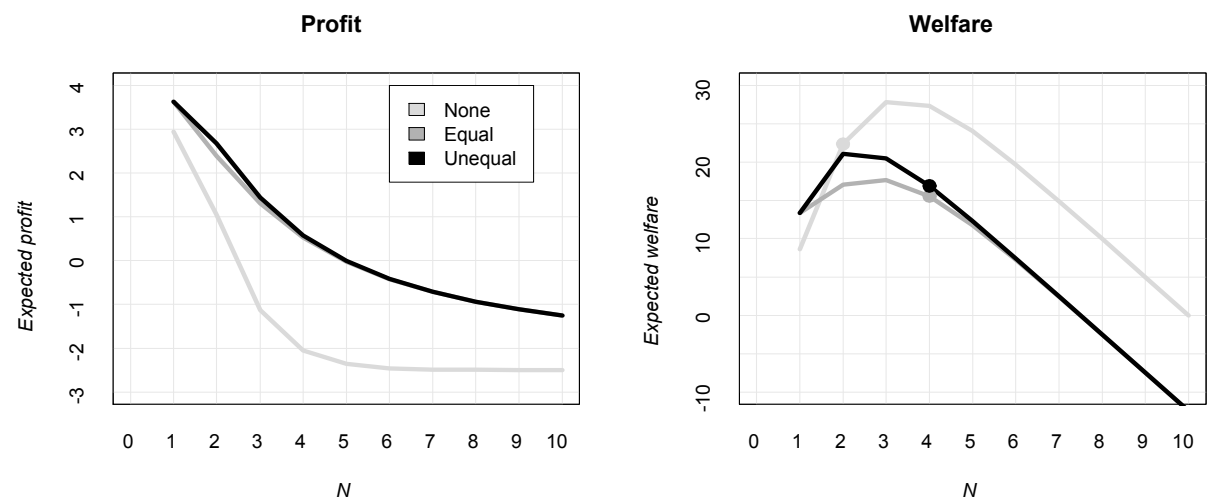

Figure 1: Illustration of a single simulation of model 1 , for $c=2.5$ and $\sigma=0.7$. The left plot shows expected profits of a research firm given that $N$ projects are undertaken for each component, under each type of clearinghouse. The right plot shows expected welfare as a function of $N$. The large dots are the equilibrium welfare levels.

inghouse increases expected profit for all $N$. In this particular case, there is very little difference in terms of profit between an equal and an unequal clearinghouse. Under no clearinghouse, the equilibrium investment level is $N=2$, while under an equal or unequal clearinghouse it is $N=4$. The right panel plots expected welfare as a function of $N$ under each type of clearinghouse, and the large dots show the equilibrium welfare levels.

In this case, the increase in investment from $N=2$ to $N=4$ would increase expected equilibrium welfare if the clearinghouse had no effect on ex post royalties. As Figure 1 shows, equilibrium welfare on the no clearinghouse curve is higher at $N=4$ compared to $N=2$ because the probabilities that both components are successfully developed and both components have competitive inventors are higher, and these gains outweigh the costs of the additional research projects. However, once changes in ex post licensing are taken into account, introducing a clearinghouse reduces equilibrium welfare for these parameter values.

Repeating this process for all combinations of $c$ and $\sigma$ within the given range allows us evaluate each type of clearinghouse in terms of the equilibrium welfare level as a function of the parameters. Figure 2 shows the results of this analysis by graphing the regions where equilibrium welfare is highest with no clearinghouse, an equal clearinghouse, or an unequal clear- 


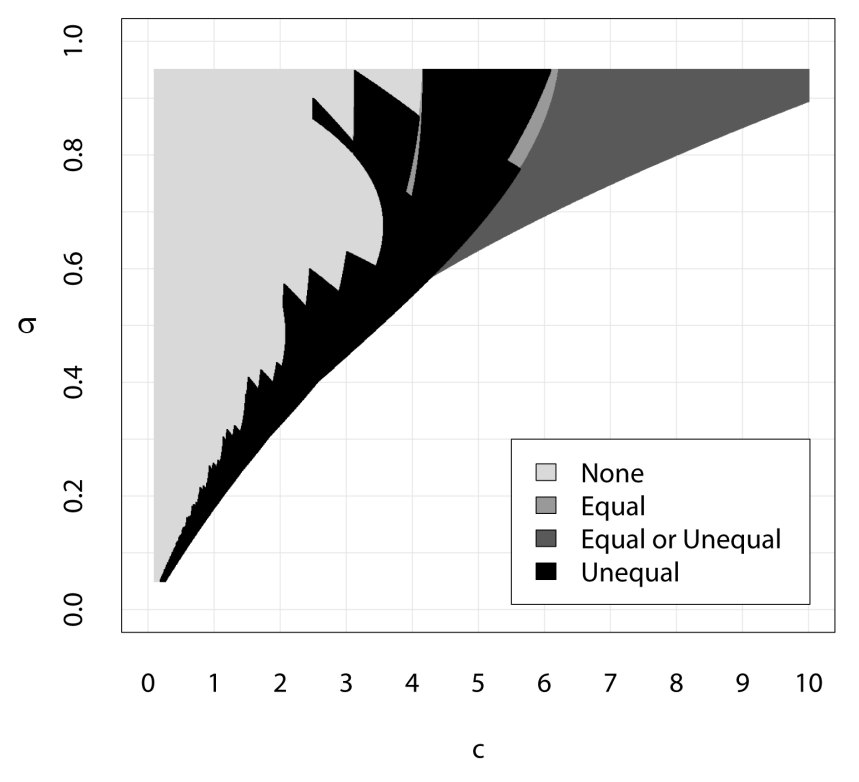

Figure 2: Parameter regions in which equilibrium expected welfare in model 1 is highest under each type of clearinghouse.

inghouse for different combinations of $c$ and $\sigma$. In general, no clearinghouse performs best when the cost per project is relatively low, or the probability of success of an individual project is relatively high. When the per-project cost increases, everything else equal, investment falls under all clearinghouse types. At sufficiently high cost levels, having a clearinghouse may increase welfare, as it increases the probability that both components are successfully invented and the product can be produced. When the probability of success increases, everything else equal, it becomes more likely that both components will have competitive inventors for a given investment level, and in this case the ex post welfare is highest with no clearinghouse. If both the project cost and probability of success are relatively high, the welfare level under an equal and unequal clearinghouse is the same, and this dominates no clearinghouse. In these cases, costs are so high that no investment occurs with no clearinghouse, while exactly one project is conducted for each component under both types of clearinghouse, in which case the equal and unequal clearinghouses produce the same welfare level.

Figure 3 further illustrates the complex structure observed at the boundaries in Figure 2 by showing the equilibrium investment level and associated 

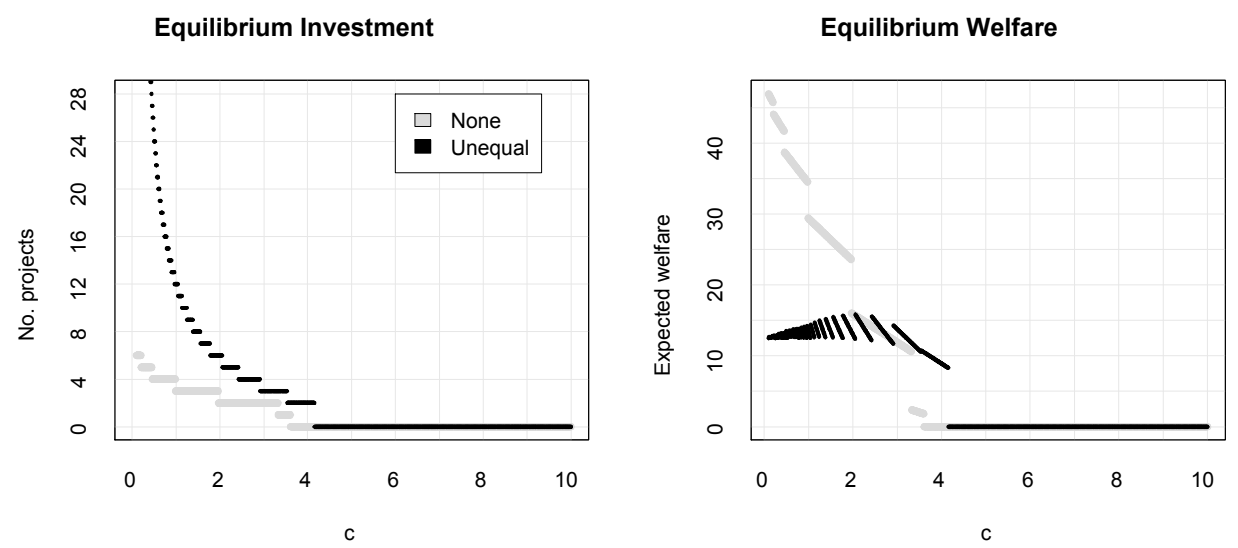

Figure 3: Equilibrium investment and welfare in model 1 as a function of the per-project cost $c$, assuming $\sigma=0.57$, for no clearinghouse and an unequal clearinghouse.

expected welfare as functions of $c$, holding $\sigma$ fixed at 0.57 , under no clearinghouse and an unequal clearinghouse. Provided that $c$ is not too high, investment occurs under both no clearinghouse and an unequal clearinghouse, and the existence of a clearinghouse generally raises the investment level for given $c$. The higher level of investment plus the fact that the clearinghouse results in higher royalties in many cases generally serves to reduce expected welfare. However, if investment did not occur with no clearinghouse but does occur with a clearinghouse, then welfare is higher with the clearinghouse. In addition, in some cases (for $c$ between around 3 to 3.5), investment levels both with and without a clearinghouse are not very high (around 2 or 3 projects). In this case, it is relatively unlikely that either component will have multiple inventors, and thus the expected welfare benefits of having a clearinghouse outweigh any expected losses.

\subsection{Model 2 simulations}

Simulations of model 2 were conducted in a similar manner as for model 1. In model 2 , for there to be some probability of production, firm A must invest and at least one component B firm must invest. Using (3) and (4) we search for the largest value of $N$ where $\pi_{A}(N) \geq 0, \pi_{B}(N) \geq 0$ and $\pi_{B}(N+1)<0$. As in model 1 , the expected profit of a component B firm converges to $-c_{B}$ as $N$ becomes large, thus an equilibrium where there is 
investment occurs if $\pi_{B}(N) \geq 0$ and $\pi_{A}(N) \geq 0$ for some relatively small $N$. As well as the linear demand royalties and welfare from Table 3, the other parameters in model 2 are $c_{A}, c_{B}, \sigma$ and $z$. In general we normalise $c_{A}$ and allow $c_{B}$ to vary. Unlike in model 1 , in model 2 the asymmetry between the component $\mathrm{A}$ and $\mathrm{B}$ research firms means that $z$ has an effect on the expected profits of both firm A and the component B research firms.

Figure 4 illustrates a single simulation of model 2, for some particular parameter values. With no clearinghouse the equilibrium is $N=3$, with an equal clearinghouse it is $N=8$ and with an unequal clearinghouse it is $N=5$. In this case, $z>1-\pi_{D} / \pi_{M}$, so following proposition 4 , the expected profits (and hence investment level) of component B firms is highest under an equal clearinghouse, followed by an unequal clearinghouse and then no clearinghouse. In all of these three cases, the expected profit of firm A is positive, so it invests. For these parameter values, expected equilibrium welfare is highest with an unequal clearinghouse. As in proposition 5, for any given $N$, an unequal clearinghouse generates the highest expected welfare level in model 2. For the parameter values shown in Figure 4, the welfare benefits of having an unequal clearinghouse compared to no clearinghouse plus the increased probability that component B is successfully developed more than offset the costs of the additional investment in component $\mathrm{B}$ that is induced. However, an equal clearinghouse would reduce expected welfare compared to no clearinghouse as it stimulates too much investment in component $\mathrm{B}$.

As noted above, the value of $z$ under an unequal clearinghouse is not neutral in this model. Given any $N \geq 2$, a higher value of $z$ increases the expected profit of firm $\mathrm{A}$ and reduces the expected profit of a component $\mathrm{B}$ research firm under an unequal clearinghouse. Thus higher $z$ will reduce investment in component $\mathrm{B}$, but make it more likely that firm A will find investing profitable, everything else equal. Figure 5 illustrates this tradeoff by showing firm A's expected profit and expected equilibrium welfare as functions of $z$, for some specific values of $c_{A}, c_{B}$ and $\sigma$. To generate this figure, for each value of $z$ in the feasible range, the equilibrium investment levels under an unequal clearinghouse were calculated in the manner described above, and the corresponding expected profits of firm A and expected welfare were calculated. The discrete steps observed in the results correspond to different discrete levels of equilibrium investment in component B. 

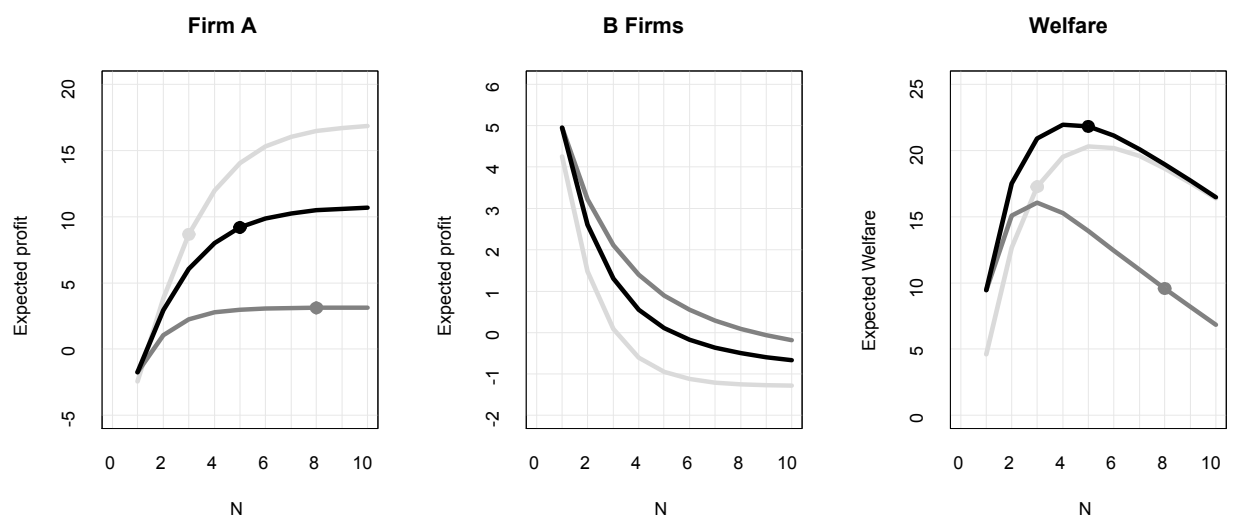

Figure 4: Illustration of a single simulation of model 2 , for $c_{A}=8, c_{B}=1.3$, $\sigma=0.5$ and $z=0.75$. The left plot shows expected profits of firm A given that $N$ projects are undertaken for component $\mathrm{B}$, under each type of clearinghouse. The middle plot shows the expected profit of a component B research firm. The right plot shows expected welfare as a function of $N$ and the large dots are the equilibrium welfare levels.

When the probability of success for component B firms $(\sigma)$ is low, Figure 5 shows that expected profits and welfare generally decline as $z$ increases. With low $\sigma$, equilibrium investment in component $\mathrm{B}$ is low, while equilibrium welfare is increasing in $N$ provided that $c_{B}$ is not too large, since additional investment would raise the probability that component $\mathrm{B}$ is invented. In this case, increasing $z$ reduces investment in component $\mathrm{B}$ and reduces expected welfare. Reduced investment in component B also negatively affects firm A in this case as it can only earn profits if component $\mathrm{B}$ is also invented. Thus when $\sigma$ is low, ex ante firm A prefers a low value of $z$ as this stimulates investment in component B, even though it may reduce firm A's ex post licensing profits.

At higher values of $\sigma$, Figure 5 shows that equilibrium expected profits of firm $\mathrm{A}$ and welfare may be increasing and then decreasing in $z$. Again increasing $z$ reduces investment in component B under an unequal clearinghouse. However, this may increase welfare if $\sigma$ is sufficiently high, since the cost savings from reduced investment can outweigh the reduced probability that component B is invented. Indeed, if $\sigma$ is very high then expected welfare and firm A's expected profit maximised by setting $z=1$. In such a 

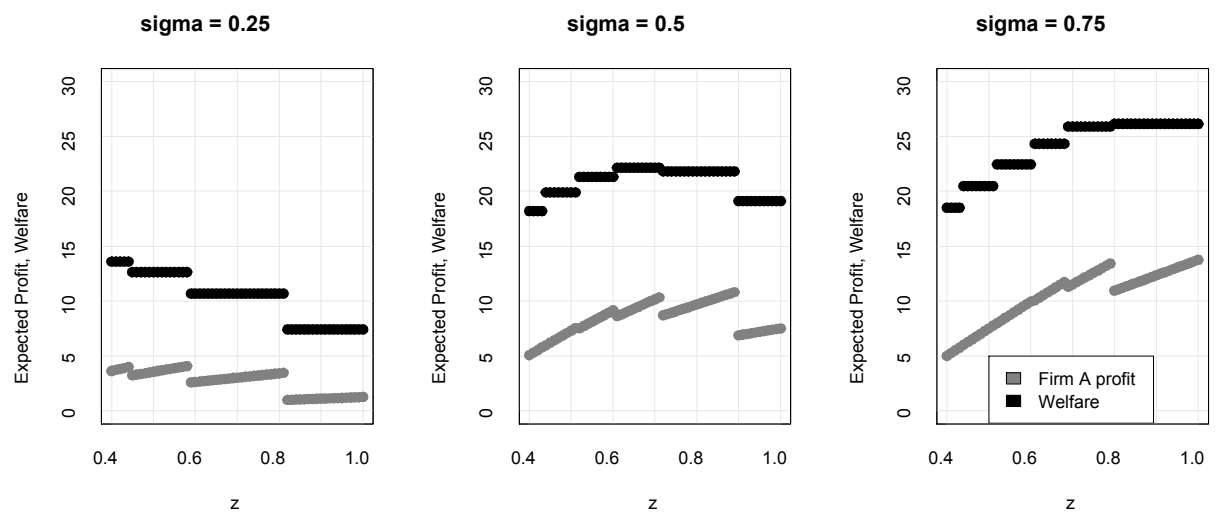

Figure 5: Firm A's expected equilibrium profit and expected equilibrium welfare under an unequal clearinghouse as a function of $z$, for $c_{A}=5$ and $c_{B}=3$.

case, investment in B is minimal since investors only get a return if they are the sole successful investor, but this does not have a large adverse effect on firm A's expected profits or expected welfare.

Figure 6 shows parameter combinations of $c_{B}$ and $\sigma$ where each type of clearinghouse performs best in terms of ex ante expected welfare, for different values of $z$, holding $c_{A}$ constant. Again we simulated the model for all combinations of $c_{B}$ between 0.1 and 10 (in increments of 0.01 ) and values of $\sigma$ between 0.05 and 0.95 (in increments of 0.001 ), for three different values in the feasible range of $z$. In total, 2,678,673 simulations of model 2 were
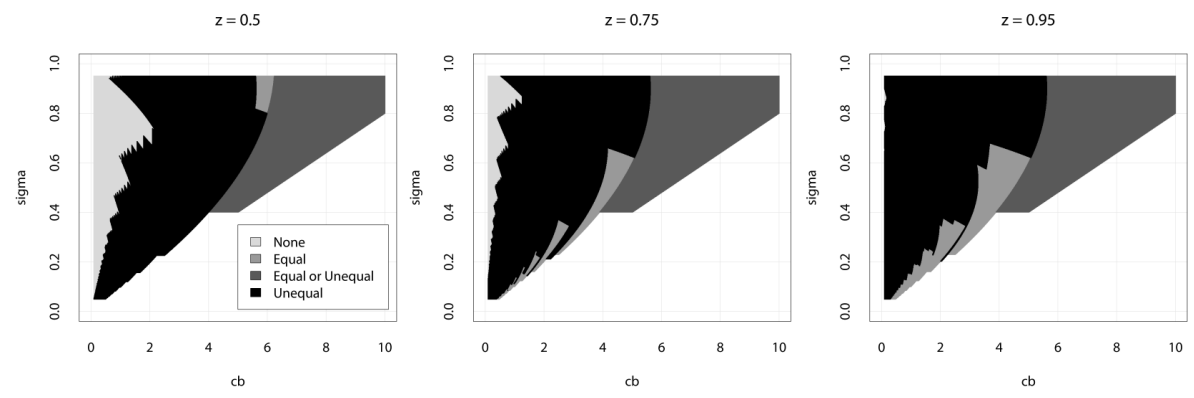

Figure 6: Parameter regions in which equilibrium expected welfare in model 2 is highest under each type of clearinghouse, for $c_{A}=5$. 
performed. In each case, the equilibrium under each type of clearinghouse was recorded and the corresponding equilibrium expected welfare level was calculated. As in model 1 , given $z$, clearinghouses generally perform best when the cost of $R \& D$ is relatively high or the probability of success is relatively low.

In addition, comparing the results in Figure 6 for different values of $z$ shows that as $z$ increases, the range of parameters where no clearinghouse performs best shrinks and the range where an unequal clearinghouse performs best expands. This is because as $z$ increases, the ex post payoffs to firms under an unequal clearinghouse and no clearinghouse become similar, except in the case where both components have a single inventor, as can be seen from Table 1. Thus the level of investment achieved by an unequal clearinghouse is similar to that with no clearinghouse when $z$ is large, but the clearinghouse increases welfare as it results in more efficient licensing when both components have a single inventor. Nevertheless, this does not necessarily mean that $z=1$ or $z$ close to 1 is the socially optimal value of $z$. For some parameter values, increasing $z$ does make an unequal clearinghouse perform better than no clearinghouse, but as shown in Figure 5 once effects on the level of investment are taken into account, the welfare-maximising value of $z$ can be anywhere within the feasible range.

Figure 6 also shows that as $z$ increases the range of parameters where an equal clearinghouse outperforms an unequal clearinghouse increases. The ex post welfare under an equal clearinghouse may be less than that of an unequal clearinghouse, as the equal clearinghouse does not result in the participation of firm A when component B has multiple inventors. However, the equal clearinghouse gives stronger incentives to component $\mathrm{B}$ firms to invest compared to an unequal clearinghouse with a high value of $z$, which may be preferable from a welfare point of view.

\section{Conclusion}

Our analysis has shown that clearinghouses can have both positive and negative effects on ex ante and ex post profits and welfare from licensing innovations. Taking a long-run perspective, the ex ante effects on expected profits and welfare are arguably the most important. In this case we showed that clearinghouses generally increase expected profits from licensing. An 
exception is when there is a unique potential inventor for one component (our model 2), in which case a clearinghouse may reduce that inventor's expected profits when investment in the other component is relatively high. Aside from this exception, clearinghouses generally increase incentives to invest in R\&D. However, as we showed, this increase in investment does not always increase ex ante expected welfare, if the benefits in terms of the increased probability that all necessary components are developed does not outweigh the additional cost of the R\&D investment and any anticompetitive effects of the clearinghouse.

The possibility that a clearinghouse reduces welfare is particularly acute in the case where royalties are distributed equally among members. If a clearinghouse does not have the ability to differentiate royalty payments to inventors whose innovations have no substitutes versus payments to those who do have competitive substitutes, the clearinghouse increases expected profits from $R \& D$ but is likely to reduce expected welfare. Therefore, we reach the policy conclusion that clearinghouses should be given flexibility in their royalty distribution scheme. Our analysis also showed that the optimal level of asymmetry of royalty payments by a clearinghouse to inventions with no substitutes versus those with substitutes varies depending on parameters such as the costs of $R \& D$ and the probability of success. If a clearinghouse spans multiple industries, for example, it may therefore be appropriate for it to use different royalty distribution arrangements in different cases, depending on industry characteristics.

Finally, our analysis highlighted some potential conflicts among different types of inventors in terms of their support for a clearinghouse. Clearinghouses are most likely to be supported by successful inventors of competitive innovations. However, their support should be viewed with some scepticism, as it is essentially a collusive device for them. On the other hand, symmetric inventors who have not yet invested and who all have an equal chance of being successful are also likely to support a clearinghouse, but this may enhance both profits and welfare if it does not induce excessive investment. Opposition to a clearinghouse is likely to come from successful inventors of a component that does not have any substitutes, or inventors who have not yet invested but have the unique ability to develop a component. In either case, an unequal royalty distribution scheme is necessary to earn their support. 


\section{References}

[1] Aoki, R. \& S. Nagaoka (2005). Coalition formation for a consortium standard through a standard body and a patent pool: Theory and evidence from MPEG2, DVD and 3G. Institute of Innovation Research, Hitotsubashi University, Working Paper WP\#05-01.

[2] Aoki, R. \& A. Schiff (2008). Promoting access to intellectual property: Patent pools, copyright collectives and clearinghouses. REDD Management, forthcoming.

[3] Buchanan, J. \& Y. Yoon (2000). Symmetric tragedies: Commons and anticommons. Journal of Law and Economics, 43: 1-13.

[4] Heller, M. \& R. Eisenberg (1998). Can patents deter innovation? The anticommons in biomedical research. Science, 280: 698-701.

[5] OECD (2002). Genetic Inventions, Intellectual Property Rights and Licensing Practices: Evidence and Policies. Downloaded from www.oecd.org/dataoecd/42/21/2491084.pdf.

[6] Shapiro, C. (2001). Navigating the patent thicket: Cross licenses, patent pools and standard setting. In Jaffe, E., Lerner, J. \& Stern, S., eds, Innovation Policy and the Economy, Volume I. MIT Press: Cambridge.

[7] Van Overwalle, G., E. van Zimmeren, B. Verbeure, G. Matthijs (2006). Models for facilitating access to patents on genetic innovations. Nature Reviews Genetics, 7: 143-154.

[8] van Zimmeren, E., B. Verbeure, G. Matthijs \& G. Van Overwalle (2006). A clearing house for diagnostic testing: The solution to ensure access to and use of patented genetic innovations? Bulletin of the World Health Organization, 84: 352-359. 